\title{
As práticas discursivas no ensino de química: um estudo das aulas dos licenciandos do programa institucional de bolsas de iniciação à docência
}

Ana Carolina Araújo da Silva anacarolina.silva@ufjf.edu.br orcid.org/0000-0002-4909-4322 (UFJF), Juiz de Fora, Minas Gerais, Brasil

Franciane Cristina Toledo Duarte francianetoledo@gmail.com

orcid.org/0000-0001-8464-5823

Escola Estadual Professor Morais (SEEMG), Belo Horizonte, Minas Gerais, Brasil

Penha Souza Silva penhadss@gmail.com orcid.org/0000-0001-5737-9566 Universidade Federal de Minas Gerais (UFMG), Belo Horizonte, Minas Gerais, Brasil

\section{RESUMO}

Este artigo apresenta as práticas discursivas identificadas em aulas de Química de licenciandos do Programa Institucional de Bolsas de Iniciação à Docência - PIBID. Essas aulas foram observadas durante o desenvolvimento do projeto Água em foco: qualidade de vida e cidadania. O objetivo da pesquisa foi compreender como as abordagens comunicativas são engendradas nas aulas do licenciandos participantes do PIBID. Para a coleta de dados foram filmadas três aulas ministradas por três bolsistas sendo cada aula em uma turma de segundo ano do Ensino Médio de uma mesma escola no município de Belo Horizonte - MG. $\mathrm{Na}$ análise de dados, utilizamos a ferramenta analítica proposta por Mortimer e Scott (2003 e 2002) para identificar as classes de abordagem comunicativa e relacioná-las com os tipos de perguntas que aconteceram nas aulas. A partir da filmagem, elaboramos mapas de episódios nos quais selecionamos um episódio de cada aula. Nestes episódios, observamos as perguntas que os licenciandos direcionaram à turma e a partir dos questionamentos realizados buscamos identificar os tipos de abordagem comunicativas que se realizavam. A análise dos dados nos permitiu identificar o esforço realizado pelos licenciandos em promover uma interação com os estudantes, emergindo assim as diferentes classes de abordagem comunicativa. Observamos também que enunciações de processo e metaprocesso facilitam o aparecimento da abordagem interativa dialógica.

PALAVRAS-CHAVE: PIBID. Abordagem Comunicativa. Formação de Professores. 


\section{INTRODUÇÃO}

Não se pode falar em melhoria na educação sem nos preocuparmos com a formação dos professores, que consideramos uma das peças mais importantes deste processo. Assim, entendemos que o Programa Institucional de Bolsa de Iniciação a Docência (PIBID) tem sido relevante na educação, pois busca contribuir de forma prática para a formação de professores. Esta pesquisa foi realizada no contexto do PIBID de Química da Universidade Federal de Minas Gerais - UFMG.

No PIBID de Química da UFMG, os licenciandos têm a oportunidade de discutir diversos temas relacionados à sua formação como professor. Um dos temas abordados durante os encontros são as práticas discursivas e suas implicações. É um assunto de grande relevância para o Ensino de Ciências, visto que as interações produzidas em sala de aula podem proporcionar e conduzir os estudantes para uma apropriação do discurso científico. Neste sentido, optamos por observar como os licenciandos participantes do PIBID têm utilizado seus conhecimentos sobre as práticas discursivas em suas intervenções na sala de aula.

O PIBID de Química ocorre na UFMG desde 2009 e conta atualmente com a participação de três escolas estaduais de Belo Horizonte, sendo que cada uma possui um professor supervisor que recebe cinco licenciandos. Os licenciandos acompanham as aulas nas escolas duas vezes por semana e participam de uma reunião semanal na UFMG, juntamente com os professores supervisores e o professor coordenador, que é um professor da licenciatura da universidade.

A ida à escola é o momento em que os licenciandos vivenciam as práticas do cotidiano escolar, participando efetivamente das atividades do professor, tanto no âmbito da sala de aula, como no seu contexto. Os encontros semanais na universidade constituem um espaço de orientação e discussão, onde os alunos expõem e discutem as atividades que são realizadas na escola, planejam novas atividades como, por exemplo, o desenvolvimento de projetos, produção de materiais para serem utilizados com os alunos e compartilhamento das dificuldades encontradas pelos colegas. É também nestes encontros que os licenciandos têm a oportunidade de conhecer o que há de mais atual no ensino de ciências, por meio de apresentações, palestras de convidados, leituras e discussões de textos selecionados pelo coordenador.

Participando do PIBID, o licenciando intensifica o diálogo entre a universidade e a escola pública, entre o aprendizado acadêmico e seu campo de trabalho, desenvolvendo a consciência crítica de professores que aprendem com a própria experiência. Além disso, nas discussões de temas atuais e inovadores no ensino de química, os licenciandos adquirem preparação para a sala de aula.

As práticas discursivas representam um tema que está cada vez mais em evidência no campo da educação em ciências (DRIVER, ASOKO, LEACH, MORTIMER e SCOTT, 1999; MONTEIRO e TEIXEIRA, 2004; SILVA, 2008; SILVA, 2009; MONTEIRO, MONTEIRO, GASPAR e VILLANI, 2012, SILVA, 2015). Para JiménezAleixandre (2006) aprender ciências é ser aprendiz das práticas discursivas da comunidade científica escolar, uma vez que a essa aprendizagem inclui uma linguagem própria e critérios para avaliar conhecimentos e métodos. Portanto, na medida em que práticas discursivas são incentivadas nas aulas de ciências, os estudantes vão se apropriando de novas formas de se expressar, adquirindo mais independência e confiança em suas ideias, além de irem assumindo atitudes mais 
científicas baseadas na atuação do professor (CANDELA, 1997). Diante da relevância do tema, surgiu o interesse em investigar como os licenciandos participantes do PIBID têm incorporado essas discussões em suas intervenções na sala de aula, na perspectiva das abordagens comunicativas. É importante ressaltar que o uso deste conhecimento é fundamental para que as aulas de química tenham um melhor direcionamento, pois a partir dessas práticas que o professor poderá proporcionar, aprimorar a interação discursiva e possibilitar uma maior apropriação do discurso científico presente nas aulas de Química.

Para identificar e compreender diferentes tipos de discurso presentes nas aulas dos licenciandos acompanhamos as aulas do projeto "Água em foco". O projeto temático "Água em foco: qualidade de vida e cidadania" é desenvolvido desde seu primeiro edital do PIBID na UFMG. Este projeto apresenta um problema aberto, na abordagem de Ciência, Tecnologia, Sociedade e Ambiente (CTSA), para que os alunos possam resolver utilizando os conhecimentos adquiridos nas aulas de Química. As atividades do projeto propõem várias questões para discussão e, como são os licenciandos que dão as aulas do projeto, consideramos que esta é uma oportunidade para que eles coloquem em prática os conhecimentos que têm sido discutidos tanto no PIBID como no curso de licenciatura.

O objetivo deste artigo é revelar como as abordagem comunicativas são produzidas nas aulas de Química de estudantes participantes do PIBID. Neste trabalho, almejamos evidenciar que a construção dos significados científicos em sala de aula promove mudanças/perguntas que envolvem os estudantes em discussão em sala de aula.

\section{REFERENCIAL TEÓRICO}

Para tornar visível as práticas discursivas dos licenciandos participantes do PIBID, utilizamos para análise, nesta pesquisa, o conceito de abordagem comunicativa presente na ferramenta analítica desenvolvida por Mortimer e Scott (2002 e 2003). Essa ferramenta tem como base a perspectiva sócio-histórica ou sociocultural de Vigotski e o conceito de "gêneros de discurso" proposto por Bakhtin (MORTIMER e SCOTT, 2002). Na perspectiva sociocultural, temos o processo de criação de significados pelos estudantes como oriundo da interação social. O processo de aprendizagem não é tratado como uma simples substituição das concepções prévias dos estudantes, mas sim como uma negociação, uma construção conjunta do conhecimento para uma internalização efetiva (MORTIMER e SCOTT, 2002). E, para tanto, as interações discursivas são de caráter fundamental.

A ferramenta para analisar e planejar aulas de ciências permite que as estratégias enunciativas dos professores sejam identificadas e descritas de acordo com cinco aspectos que se inter-relacionam. São eles: as intenções do professor, o conteúdo, a abordagem comunicativa, os padrões de interação e a as intervenções do professor (Quadro 1). 


\begin{tabular}{|c|c|}
\multicolumn{2}{c}{ Quadro 1 - Aspectos da Análise } \\
\hline I. Focos do ensino & Aspectos da Análise \\
\hline II. Abordagem & 1. Intenções do professor / 2. Conteúdo \\
\hline III. Ações & 3. Abordagem comunicativa \\
\hline
\end{tabular}

Fonte: Mortimer e Scott (2002).

De acordo com o Quadro 1, os aspectos da análise são divididos em I - Focos do Ensino, II - Abordagem e III - Ações. Em focos do ensino são avaliados as intenções do professor e o conteúdo. Na abordagem é considerada a forma de como abordar o tema, como podemos conduzir o discurso em sala de aula. E em ações, são identificados os padrões de interação e as intervenções do professor para a compreensão do tema a ser trabalhado. Como mencionado, neste artigo, apresentamos o conceito de abordagem comunicativa e de padrões de interação que auxiliaram na análise de dados desta pesquisa.

\section{ABORDAGEM COMUNICATIVA}

Como já mencionado o referencial teórico deste artigo é a ferramenta analítica proposta por Mortimer e Scott $(2002,2003)$. Os autores da ferramenta indicam que o conceito de "Abordagem Comunicativa" é central na estrutura analítica fornecendo a perspectiva sobre como o professor trabalha as intenções e o conteúdo do ensino por meio das diferentes intervenções pedagógicas que resultam em diferentes padrões de interação. Mortimer e Scott (2002) identificam quatro classes de Abordagem Comunicativa que são definidas por meio da caracterização do discurso entre professor e alunos ou entre alunos em termos de duas dimensões: discurso dialógico ou de autoridade e discurso interativo ou nãointerativo.

Para Mortimer e Scott (2002), quando um professor interage com os estudantes em sala de aula as intervenções podem ser caracterizadas em termos de dois extremos. $O$ discurso pode ser dialógico ou de autoridade. No primeiro extremo, o professor considera o ponto de vista, os conhecimentos prévios, dos estudantes. Nesse momento, mais de uma "voz" é ouvida e considerada, acontece uma interação entre as diferentes ideias presentes na sala de aula. No segundo extremo, o professor vai considerar na sua fala e na do estudante apenas o ponto de vista do discurso científico que está sendo construído no plano social de sala de aula. Este segundo tipo de interação constitui uma abordagem comunicativa de autoridade, na qual apenas uma "voz" é ouvida, o discurso da ciência, e não há interanimação de ideias (MORTIMER; SCOTT, 2002).

Os autores argumentam que "na prática, qualquer interação provavelmente contém aspectos de ambas as funções, dialógica e de autoridade" (MORTIMER; SCOTT, 2002). Para distinguirmos entre as abordagens dialógicas e de autoridade presentes em sala de aula temos que compreender que em uma sequência discursiva a abordagem pode ser identificada como dialógica ou de autoridade independentemente de ter sido enunciada por um único indivíduo ou interativamente (MORTIMER; SCOTT, 2002). O que isso significa? Que um discurso 
pode ser dialógico e ser enunciado por apenas uma pessoa ou ser de autoridade, mas que haja a interação de mais de uma pessoa.

O que torna o discurso funcionalmente dialógico é o fato de que ele expressa mais de um ponto de vista - mais de uma "voz" é ouvida e considerada - e não que ele seja produzido por um grupo de pessoas ou por um indivíduo solitário (MORTIMER; SCOTT, 2002). Esse último aspecto está relacionado à segunda dimensão da abordagem comunicativa, que distingue entre o discurso interativo, aquele que ocorre com a participação de mais de uma pessoa, e o discurso nãointerativo, que ocorre com a participação de uma única pessoa. Essas duas dimensões podem ser combinadas para gerar quatro classes de Abordagem Comunicativa (MORTIMER; SCOTT, 2002).

Para Mortimer e Scott (2002), embora cada uma dessas quatro classes estejam relacionadas ao papel do professor ao conduzir o discurso da classe, elas são igualmente aplicáveis para caracterizar as interações que ocorrem apenas entre estudantes, por exemplo, em pequenos grupos. As quatros classes de abordagem comunicativa definidas por Mortimer e Scott (2002), são:

a. Interativo/dialógico: professor e estudantes exploram ideias, formulam perguntas autênticas, consideram e trabalham diferentes pontos de vista.

b. Não-interativo/dialógico: professor reconsidera, na sua fala, vários pontos de vista, destacando similaridades e diferenças.

c.Interativo/de autoridade: professor geralmente conduz os estudantes por meio de uma sequência de perguntas e respostas, com o objetivo de chegar a um ponto de vista específico.

d. Não-interativo/de autoridade: professor apresenta um ponto de vista específico (MORTIMER; SCOTT, 2002, p. 288).

Para que o professor possa garantir que as diferentes formas de abordagem ocorram em suas aulas, ele precisa trabalhar de forma que seja estabelecido um contrato didático com a turma, para que os alunos correspondam às interações. Ou seja, os alunos precisam se acostumar a participar naturalmente das discussões. Isso também não é tarefa fácil, o professor precisa construir isso na sala de aula. Este contrato didático está realmente em vigor quando os estudantes expõem suas opiniões naturalmente, sem se importar se vão parecer certos ou errados, e o professor por sua vez sempre incentiva os estudantes a continuarem a discussão, valorizando as opiniões dos estudantes e mantendo o diálogo. Quando isso acontece de maneira natural, entendemos que esse contrato didático, ainda que "invisível", está em real funcionamento.

O que comumente acontece é que, em uma abordagem interativa de autoridade, o professor sempre avalia os comentários dos estudantes. Entretanto, quando os estudantes percebem que estão sempre sendo avaliados, vão se tornando cada vez mais inibidos de dizer o que pensam. Já na abordagem interativa dialógica, o professor pode considerar os diversos pontos de vista, por mais que sejam errôneos e ingênuos. $O$ professor em vez de avaliar imediatamente o ponto de vista do aluno, pode fornecer uma chance para que ele discuta seu próprio ponto de vista, explique melhor e vá, ele próprio, percorrendo o caminho para chegar a uma explicação mais próxima do ponto de vista da ciência. Ainda que a abordagem interativa de autoridade seja importante, pois é com ela que o 
professor consegue guiar os estudantes pelo caminho que ele pretende, a abordagem interativa dialógica é fundamental para que o aluno tenha segurança em expor seus pontos de vista, sentir que os mesmos são valorizados, para que ele possa caminhar para o conhecimento que vai adquirir partindo daquilo que ele já sabe.

\section{PADRÕES DE INTERAÇÃO}

O padrão de interação mais comumente observado é o chamado de tríade IR-A - Iniciação-Resposta-Avaliação, no qual o professor inicia uma interação, o aluno corresponde e o professor avalia. Porém há outros padrões que são melhor aproveitados em uma abordagem interativa dialógica que são as cadeias I-R-P-RP-R-P(...) e I-R-F-R-F-R-F(...) onde P significa uma interação do professor com intuito de dar prosseguimento à fala do aluno e $\mathrm{F}$ significa um feedback para que o aluno elabore sua fala.

Para uma caracterização mais detalhada dos padrões de interação, também é possível categorizar os tipos de iniciação e de resposta. Tendo como referência os trabalhos de Mehan (1997) e Silva (2009), temos quatro possibilidades de iniciação para uma interação:

\section{1 - INICIAÇÃO DE ESCOLHA}

A iniciação de escolha corresponde a uma enunciação na qual o professor espera que o estudante concorde ou discorde de alguma coisa ou escolha entre algumas opções. Por exemplo, quando o professor pergunta: "essa substância é ácida ou básica?", "a reação é endotérmica ou exotérmica?".

\section{2 - INICIAÇÃO DE PRODUTO}

A iniciação de produto é aquela que demanda do estudante uma resposta que seja um nome, um lugar, uma data, uma cor, etc. Por exemplo, "qual gás está sendo liberado nessa reação química?", "qual a fórmula da água?".

\section{3 - INICIAÇÃO DE PROCESSO}

Este tipo de iniciação normalmente trata de uma pergunta do tipo "por que", "como", "o que acontece", que demanda do estudante uma explicação ou uma descrição de alguma coisa. Exemplo, "o que acontece quando misturamos água e óleo?".

\section{4 - INICIAÇÃO DE METAPROCESSO}

Esse tipo de iniciação é identificado quando o professor pede uma reflexão do estudante, com questionamentos do tipo "explique melhor seu raciocínio" ou "como você chegou a essa conclusão" ou "o que você quis dizer com isso?". De forma a pedir ao estudante que reformule seus enunciados e exponha seu raciocínio.

As respostas são categorizadas dessa mesma forma (escolha, produto, processo e metaprocesso), mas isso não significa que um tipo de iniciação necessariamente resultará no mesmo tipo de resposta. E existe também a "pergunta retórica", que acontece quando o professor faz perguntas, mas não deixa espaço para resposta (DUARTE et al., 2014). 


\section{CONTEXTO DA PESQUISA}

Esta pesquisa está inserida em um dos projetos desenvolvidos pelo PIBID de Química que é o projeto "Água em foco: qualidade de vida e cidadania". Esse projeto é desenvolvido no PIBID - Química desde o primeiro edital. As aulas, as apostilas e as práticas experimentais do projeto são planejadas em conjunto (licenciandos e supervisores), discutidas e então desenvolvidas pelos licenciandos nas escolas. Essa é a oportunidade dos licenciandos vivenciarem a prática docente, sob a supervisão de seu professor orientador, e experimentar as orientações discutidas no curso de licenciatura e no PIBID.

No projeto "Água em foco" existem várias sequências de aulas que foram planejadas para proporcionar aos alunos formas de reconhecer e analisar a qualidade da água. Dentre as sequências desenvolvidas, uma delas trabalha o pH, discutindo os conceitos de ácido e base, a construção de uma tabela de pH em uma atividade prática e as discussões sobre como o pH pode alterar a qualidade da água e a vida presente em um ecossistema aquático. Este projeto considerou a Lagoa da Pampulha, cartão postal de Belo Horizonte, como contexto de análise da água.

As escolas participantes recebem o material necessário para o desenvolvimento do projeto. Este material se constitui das apostilas para todos os estudantes e kits que contém vidrarias, reagentes e outros materiais necessários para a realização das atividades experimentais.

\section{SUJEITOS DA PESQUISA}

Para esta pesquisa selecionamos três licenciandos em Química que já estavam no PIBID há mais de um ano e que eram supervisionados pela mesma professora, com experiência de dois anos no PIBID. Sendo assim, tanto os alunos quanto a professora já estavam entrosados, acostumados com o projeto, como também já haviam participado de várias palestras e debates sobre temas variados. A seguir apresentaremos os licenciandos participantes da pesquisa Beatriz ${ }^{1}$, Sara e Daniel.

Beatriz, aluna do sétimo período, desde início do curso se interessou em participar de projetos na área de educação. Há um ano ela trabalha como monitora em cursinhos pré-vestibular e eventualmente também dá aulas. Seu interesse em participar do PIBID foi para enriquecer a sua formação acadêmica.

Sara, então cursando o quinto período, escolheu este curso pela vontade de ser professora. Teve no PIBID sua primeira experiência em sala de aula e, segundo a mesma, foi por isso que quis participar do projeto, para se preparar e ganhar experiência antes de assumir uma turma em uma escola.

Daniel, estudante do quarto período do curso, descobriu sua vontade de ser professor durante a sua participação no PIBID, pois segundo ele, antes de participar do projeto, ainda não sabia se queria mesmo ser professor e não tinha nenhuma experiência com sala de aula. 


\section{TURMA INVESTIGADA}

As turmas nas quais projeto foi desenvolvido eram do segundo ano do Ensino Médio. Nessa escola, devido ao seu espaço físico, existem turmas que têm entre 25 e 30 estudantes, fato que, de alguma forma, favorece a atuação do professor e consequentemente a dos licenciandos. As turmas observadas neste trabalho eram tranquilas e algumas vezes participativa. Os licenciandos já vinham acompanhando essas turmas durante todo o ano e revezavam as aulas em cada turma, sendo assim, já havia certa familiaridade entre eles e os estudantes.

\section{COLETA DE DADOS}

Para a coleta de dados acompanhamos as aulas ministradas por três diferentes licenciandos, durante o projeto "Água em Foco". A aula analisada neste trabalho encontra-se na sequência de três aulas desenvolvida sobre o tema $\mathrm{pH}$. Filmamos os três licenciandos que planejaram e aplicaram essa mesma aula em turmas diferentes da mesma escola.

Vimos a necessidade de filmar essas aulas, para registrar os episódios desencadeados e não perder os detalhes. Portanto, fomos à escola e realizamos as filmagens e, posteriormente, o conteúdo das mesmas foi transferido para o computador.

\section{ANÁLISE DE DADOS}

A primeira etapa da análise consistiu em assistir aos vídeos e elaborar os mapas de episódios dos mesmos. Os mapas de episódios foram construídos para identificar as formas de interação estabelecidas, os recursos materiais utilizados, as fases da atividade, a posição dos participantes em relação uns aos outros, as ações realizadas pelos participantes, algumas observações consideradas pertinentes e selecionar episódios par análise. De acordo com Mortimer et al. (2007), os episódios podem ser entendidos como segmentos do discurso da sala de aula com fronteiras temáticas bem nítidas. Todavia, há um conjunto de características que permitem a delimitação dos episódios, além do tema, sendo elas: a fase da atividade na qual o episódio tem lugar, as ações dos participantes, as formas como os participantes se posicionam no espaço físico no qual ocorrem as interações e as formas pelas quais os participantes interagem entre si e com os recursos materiais utilizados. Nesta pesquisa, demarcamos os episódios a partir da iniciação realizada pelos licenciandos.

A partir dos mapas de episódios, foram observados os caminhos que as aulas tomaram, a forma como os professores as conduziam e, também, as interações estabelecidas. Neste momento, observamos que no decorrer das aulas, os licenciandos fazem várias perguntas direcionadas aos alunos e por isso, optamos dar um foco especial a essas perguntas. Que tipos de perguntas são essas? Elas favorecem algum tipo de abordagem comunicativa?

Utilizando ainda os mapas de episódios, observamos a ocorrência das classes 
não interativa e dialógica, não interativa e de autoridade). As observações encontram-se na análise dos dados.

\section{AS AULAS DOS LICENCIANDOS}

Nesta seção, apresentamos a análise dos dados e descreveremos a aula sobre a atividade $\mathrm{pH}$, dos licenciandos Beatriz, Sara e Daniel. Consideramos na análise a abordagem utilizada pelos licenciandos e como os tipos de perguntas realizadas pelo professor influenciam nessa abordagem.

A aula analisada encontra-se na sequência desenvolvida sobre o pH. Na aula anterior os alunos construíram uma escala de $\mathrm{pH}$ utilizando extrato de repolho roxo e soluções de $\mathrm{pH}$ conhecidos, sendo o primeiro momento desta aula uma retomada do que os alunos recordam sobre a aula prática que tiveram sobre o assunto. Em seguida, os licenciandos mostram que os ácidos e bases estão muito presentes no dia a dia e pedem aos alunos que citem exemplos dessas substâncias no seu cotidiano. A partir daí apresentam os conceitos de ácidos e bases propostos por Arrhenius, contam um pouco da história sobre essa classificação e trabalham a matemática envolvida nos cálculos de pH. Após esse momento, os licenciandos retomam o assunto da aula prática discutindo com os estudantes como funciona um indicador de $\mathrm{pH}$. Para finalizar a aula, os licenciandos realizam um experimento, proposto na apostila do projeto, que consiste em deixar um ovo mergulhado em vinagre por aproximadamente uma semana, retomando a discussão central do projeto que é a qualidade da água. Esse fechamento permite a discussão sobre a influência do pH na qualidade da água, na vida aquática e na reprodução dos peixes.

Esta aula foi desenvolvida pelos três licenciandos em turmas diferentes da mesma escola. Podemos observar particularidades nas aulas de cada um e, por isso, discutiremos sobre cada uma separadamente.

A análise dos mapas de episódios das aulas selecionadas indica que os licenciandos fazem várias perguntas direcionadas aos alunos. Para ter uma visão geral dessas perguntas, foi realizada a transcrição de todas as perguntas realizadas pelos professores durante a aula (a transcrição das perguntas encontra-se em Anexo I). As perguntas foram então classificadas e estão apresentadas no Quadro 2.

Quadro 2: Quantidade de vezes que cada tipo de pergunta apareceu na aula de cada licenciando.

\begin{tabular}{|c|c|c|c|}
\hline Professor/ Tipo de Pergunta & Beatriz & Sara & Daniel \\
\hline Escolha & 6 & 6 & 0 \\
\hline Produto & 16 & 15 & 5 \\
\hline Processo & 5 & 5 & 7 \\
\hline Metaprocesso & 0 & 0 & 0 \\
\hline
\end{tabular}

Fonte: DUARTE (2013).

A partir da análise das iniciações presentes nas aulas dos licenciando, nos questionamos: essas perguntas estariam introduzindo uma abordagem comunicativa na aula? O discurso dialógico esteve presente nessas aulas? A seguir apresentamos a análise de cada aula, observando como as perguntas ajudaram, 
ou não, no desenvolvimento da prática discursiva e, também, como os discursos foram construídos.

\section{Aula de Beatriz}

Em sua aula, a licencianda Beatriz direcionou aos estudantes um total de vinte e sete perguntas, cujos tipos são especificados no Quadro 3, que apresenta, a transcrição de um episódio desta aula.

Quadro 3: Episódio da aula da licencianda Beatriz.

\begin{tabular}{|c|c|c|c|}
\hline Turno & Tempo & Falante & Transcrição \\
\hline 1 & $13 \mathrm{~min} 30 \mathrm{~s}$ & Professora & $\begin{array}{l}\text { Alguém sabe me falar porque que a gente está } \\
\text { analisando esse } \mathrm{pH} \text { ? }\end{array}$ \\
\hline 2 & & Aluna & $\begin{array}{l}\text { Para quando a gente quiser saber o } \mathrm{pH} \text { de alguma } \\
\text { coisa a gente pode calcular. }\end{array}$ \\
\hline 3 & & Professora & $\begin{array}{l}\text { Isso, mas qual era o nosso enfoque principal } \\
\text { quando o projeto começou? }\end{array}$ \\
\hline 4 & & Alunos & A água. A água da lagoa da Pampulha. \\
\hline 5 & & Professora & $\begin{array}{l}\text { Isso, o nosso foco de interesse é a água da lagoa } \\
\text { da Pampulha. Então o que nós estamos fazendo? } \\
\text { Estudando todos os parâmetros físico-químicos } \\
\text { relacionados à água. E o pH é um dos parâmetros } \\
\text { que analisam a qualidade da água. Alguém sabe } \\
\text { me dizer se é em alto ou baixo pH que a vida } \\
\text { aquática consegue sobreviver? (...) } \\
\text { O que vocês acham que acontece com a } \\
\text { reprodução dos peixes? } \\
\text { Olha só o que eu tenho aqui, peguei um ovo de } \\
\text { galinha e coloquei no vinagre. O que é o vinagre? }\end{array}$ \\
\hline 6 & & Alunos & Ácido. \\
\hline 7 & & Professora & $\begin{array}{c}\text { Isso, ai eu coloquei o ovo da galinha dentro do } \\
\text { vinagre. O que está acontecendo aqui? }\end{array}$ \\
\hline 8 & & Alunos & Está inchando. Corroendo o ovo. Está com bolhas. \\
\hline 9 & & Professora & $\begin{array}{l}\text { Houve formação de bolhas né? Isso eu posso falar } \\
\text { que está ocorrendo o quê? }\end{array}$ \\
\hline 10 & & Alunos & Que está corroendo o ovo. \\
\hline 11 & & Professora & Está tendo alguma evidência de reação química? \\
\hline 12 & & Alunos & As bolhas. \\
\hline 13 & & Professora & Sim! A formação do gás. \\
\hline 14 & & Alunos & Qual gás que está sendo formado? \\
\hline 15 & & Professora & $\begin{array}{l}\text { Isso que nós vamos ver, a casca do ovo é formada } \\
\text { de que? Alguém sabe? }\end{array}$ \\
\hline 16 & & Alunos & Cálcio \\
\hline 17 & & Professora & $\begin{array}{l}\text { Carbonato de cálcio. Que se dissocia em } \mathrm{Ca}^{2+} \mathrm{e} \\
(\mathrm{CO})^{2-} \text {. E o que tem lá no meio? Não é ácido? O } \\
\text { carbonato de cálcio reagindo com o vinagre, olha } \\
\text { só o que vai formar. O que vai formar aqui? Como }\end{array}$ \\
\hline
\end{tabular}




\begin{tabular}{|c|c|c|c|}
\hline & & $\begin{array}{r}\text { vamos neutralizar esse -2 aqui? Esse ácido que } \\
\text { formou aqui é muito instável e ele se decompõe } \\
\text { em } \mathrm{CO}_{2} \text { e água, então esse gás que a gente vê } \\
\text { aqui é o } \mathrm{CO}_{2} .\end{array}$ \\
$\begin{array}{r}\text { Agora pensa, os peixes se reproduzem na forma } \\
\text { de ovos, se tiver num pH muito baixo, o peixe vai } \\
\text { conseguir reproduzir? }\end{array}$ \\
\hline 18 & & Aluna & Não. \\
\hline 19 & $20 \min 50$ s & Professora & $\begin{array}{r}\text { Porque o ácido vai reagir com a casca do ovo e vai } \\
\text { matar o peixinho. }\end{array}$ \\
\hline
\end{tabular}

Fonte: DUARTE (2013).

Neste episódio podemos perceber a importância de se estabelecer o contrato didático na sala de aula. Ainda que haja um esforço da professora em fazer perguntas que poderiam gerar discussões, muitas vezes os alunos não respondem a essas perguntas. Por exemplo, a professora pergunta "O que vocês acham que acontece com a reprodução dos peixes?" (turno 5) e nenhum aluno responde. Podemos perceber também a intenção de introduzir um discurso interativo, por exemplo, quando ela pergunta "Agora pensa, os peixes se reproduzem na forma de ovos, se tiver num pH muito baixo, o peixe vai conseguir reproduzir?" - pergunta de escolha (turno 17). Os alunos respondem que não, mas no lugar de dar prosseguimento ao debate, dando oportunidade dos alunos explicarem sua resposta, utilizando uma pergunta de meta processo, como "explique por que não?", a professora já confirma a resposta deles "Por que o ácido vai reagir com a casca do ovo e vai matar o peixinho." (turno 19), finalizando a interação estabelecida e partindo para um discurso de autoridade. Isto não nos surpreende, pois mesmo professores experientes, apresentam este comportamento na sala de aula. Daí a importância de o licenciando, futuro professor, ter compreensão da ferramenta analítica de análise do discurso proposta por Mortimer e Scott (2002 e 2003). Acreditamos que a ferramenta poderá ajudá-lo a manter o diálogo com o estudante.

Aula de Sara

$\mathrm{Na}$ aula da licencianda Sara identificamos também várias perguntas direcionadas aos estudantes, sendo um total de vinte e seis durante a aula. Uma dessas perguntas "então como será que funciona o extrato de repolho roxo?", desencadeia uma interação, como podemos observar na transcrição de um episódio da aula, no Quadro 4.

Quadro 4: Episódio da aula da licencianda Sara.

\begin{tabular}{|c|c|c|c|}
\hline Turno & Tempo & Falante & Transcrição \\
\hline 1 & $22 \mathrm{~min} 00 \mathrm{~s}$ & Professora & $\begin{array}{l}\text { O indicador, ele vai ter uma forma ácida, } \mathrm{HA} \text {, } \\
\text { que tem uma cor } \mathrm{A} \text {. E em água ele vai se } \\
\text { dissociar com todo ácido e vai formar } \mathrm{H}^{+} \text {e } \mathrm{A}^{-} \text {. Só } \\
\text { que esse } \mathrm{A}^{-} \text {aqui, ele vai ter uma cor } \mathrm{B} \text {. Então, o } \\
\text { indicador ele funciona assim, ele tem duas } \\
\text { formas, uma forma que ele tem uma cor } \mathrm{A} \text { e } \\
\text { depois que acontece a reação ele tem uma } \\
\text { outra forma que tem uma outra cor. Então é }\end{array}$ \\
\hline
\end{tabular}




\begin{tabular}{|c|c|c|c|}
\hline & & & $\begin{array}{c}\text { assim que todo indicador vai funcionar. Mas, } \\
\text { nosso indicador, o extrato de repolho roxo, } \\
\text { tinha só duas cores? }\end{array}$ \\
\hline 2 & & Alunos & Não. \\
\hline 3 & & Professora & Ele mostrava que cores? \\
\hline 4 & & Alunos & Roxo, verde, amarelo, vermelho, rosa \\
\hline 5 & & Professora & $\begin{array}{l}\text { Várias cores, não é? E eu consigo explicar o } \\
\text { extrato de repolho roxo como indicador só } \\
\text { usando essa reação aqui? Não, porque aqui eu } \\
\text { estou mostrando duas cores, então como será } \\
\text { que funciona o extrato de repolho roxo? Ideias? } \\
\text { Não é assim, simplesmente assim, tem uma cor } \\
\text { que vira outra. Mas vocês têm uma ideia de } \\
\text { como vai funcionar um extrato que muda para } \\
\text { várias cores, que tem uma faixa com várias } \\
\text { cores diferentes? }\end{array}$ \\
\hline 6 & & Aluno & As cores misturam. \\
\hline 7 & & Professora & Mistura de cores. \\
\hline 8 & & Aluna & Muda de A e B e depois muda mais. \\
\hline 9 & & Professora & $\begin{array}{c}\text { Você acha que é a mistura das cores, certo? E } \\
\text { você acha que depois disso vai mudar para mais } \\
\text { e para mais. }\end{array}$ \\
\hline 10 & & Alunos & Não é a mistura de cores. \\
\hline 11 & & Professora & $\begin{array}{c}\text { Cadê aquela tabelinha que vocês têm? Da } \\
\text { escala? Se fosse a mistura da cor, digamos a } \\
\text { soma da cor, aqui seria amarelo e aqui seria } \\
\text { vermelho. A cor do meio então, seria quando } \\
\text { isso aqui fosse igual a isso aqui, qual a cor que } \\
\text { tinha que ser aqui no meio? }\end{array}$ \\
\hline 12 & & Alunos & Laranja. \\
\hline 13 & & Professora & E é laranja? \\
\hline 14 & & Alunos & Não \\
\hline 15 & & Professora & É... \\
\hline 16 & & Alunos & Roxo. \\
\hline 17 & $26 \mathrm{~min} 00 \mathrm{~s}$ & Professora & $\begin{array}{l}\text { Azul. É. O pH } 7 \text { é azul, então não é a mistura de } \\
\text { cores. Então vamos pensar no que você falou. } \\
\text { Daqui ele reage de novo e reage de novo. Na } \\
\text { verdade, o extrato de repolho roxo, ele tem } \\
\text { uma substância que chama antocianina, que } \\
\text { não vem ao caso agora a estrutura dela, mas ela } \\
\text { vai reagir quando você adicionar } \mathrm{H}^{+} \mathrm{ou} \mathrm{OH}^{-} \text {, ou } \\
\text { seja, um ácido ou uma base, ele vai formar } \\
\text { outra estrutura e depois vai adicionar de novo e } \\
\text { vai formar outra estrutura, e cada estrutura } \\
\text { dessa tem uma cor. Do jeito que você falou. É } \\
\text { assim que funciona o extrato de repolho roxo. }\end{array}$ \\
\hline
\end{tabular}


Neste episódio, podemos observar que a professora faz uma pergunta e obtém da turma duas respostas diferentes (turno 5). Ela então considera as duas respostas e decide discutir sobre cada uma separadamente. Em um primeiro momento, a professora caminha com a turma numa investigação sobre a primeira ideia e conclui, junto com os estudantes, que essa não é a melhor explicação para o fenômeno que eles estão estudando. Em um segundo momento, a professora considera a outra ideia e afirma que ela é a melhor explicação para o fenômeno.

Podemos observar neste episódio, uma pergunta de processo que desencadeia uma abordagem interativa e dialógica, que finaliza com uma abordagem não interativa e de autoridade, quando a professora confirma a resposta de uma aluna e dá continuidade à explicação do fenômeno. Este é um aspecto que chama a atenção, pois mesmo professores muito experientes tendem a responder imediatamente ao aluno com a resposta "certa" ou ignorar a resposta que não interessa dando um feedback apenas para a resposta que interessa. Assim vemos o esforço da licencianda em trabalhar as duas respostas conforme as discussões realizadas nos encontros do PIBID.

Aula de Daniel

Em sua aula, Daniel direcionou a turma um total de doze perguntas dos tipos produto e processo. Algumas dessas perguntas podem ser observadas no episódio relatado no Quadro 5.

Quadro 5: Episódio da aula do licenciando Daniel.

\begin{tabular}{|c|c|c|c|}
\hline Turno & Tempo & Falante & Transcrição \\
\hline 1 & $24 \min 17 \mathrm{~s}$ & Professor & $\begin{array}{l}\text { Quando vocês adicionaram ácido, vinagre, de } \\
\text { que cor ficou? }\end{array}$ \\
\hline 2 & & Alunos & Vermelho. Rosa. \\
\hline 3 & & Professor & $\begin{array}{l}\text { Quando vocês adicionaram soda cáustica, de } \\
\text { que cor ficou? }\end{array}$ \\
\hline 4 & & Alunos & Vermelho. \\
\hline 5 & & Professor & A soda cáustica ficou vermelho? $\mathrm{NaOH}$. \\
\hline 6 & & Aluno & Não, ficou verde. \\
\hline 7 & & Professor & $\begin{array}{l}\text { Quando vocês adicionaram o Hidróxido de } \\
\text { Amônio? }\end{array}$ \\
\hline 8 & $26 \min 20 \mathrm{~s}$ & Aluna & Verde também. Outro verde. \\
\hline
\end{tabular}

Fonte: DUARTE (2013).

Este episódio permite identificar várias perguntas que podem ser classificadas como elicitações de produto. Em seus trabalhos, Mehan (1979) chama a atenção para as demandas de escolha ou produto que tendem a elicitar respostas curtas constituídas por uma única palavra, que são avaliadas pelos professores, gerando sequências do tipo I-R-A (ALMEIDA e GIORDAN, 2012). Desta forma, observamos que é favorecida a abordagem interativa e de autoridade, pois o professor interage com os estudantes, mas considera apenas um ponto de vista, que é o da ciência. Notamos que na pergunta "Quando vocês adicionaram soda cáustica, de que cor ficou?" (turno 3), que a resposta dos alunos não foi a resposta esperada pelo 
professor, então ele questiona "A soda cáustica ficou vermelha?" (turno 5), repetindo a fala dos alunos como uma forma de avaliação. Notamos que a avaliação foi entendida, pois os alunos imediatamente responderam "Não, ficou verde." (turno 6) e então ele prossegue com sua fala.

Comparando as aulas do Daniel, com as outras licenciandas, observamos que este apresenta mais dificuldades em conduzir as aulas de forma mais dialógica. Isto fica evidente no fato de usar praticamente perguntas de produto. Ainda que ele faça um esforço em conduzir as aulas de forma interativa, encontra dificuldade em sair do discurso de autoridade fazendo uma aula mais dialógica. Entendemos que esta é uma dificuldade do licenciando.

\section{CONSIDERAÇÕES FINAIS}

Sabemos que o ensino de ciências não pode ser uma mera transmissão de conceitos científicos. Pois os estudantes aprendem de uma forma mais significativa quando participam efetivamente da construção do próprio conhecimento, interagindo com os colegas e considerando o conhecimento que eles já possuem. E para que a aprendizagem ocorra desta forma, entendemos que é interessante que as quatro classes de abordagem comunicativa estejam presentes na aula, proporcionando ao aluno a oportunidade de participar, compartilhando seus pensamentos, entendimentos, necessidades e dificuldades. Neste sentido, o professor pode conduzir sua aula da maneira que julgar mais interessante para que os estudantes cheguem ao discurso científico.

Compreendemos que não é fácil para o professor dar "voz" ao estudante favorecendo o discurso interativo e dialógico de forma a caminhar para o discurso da ciência que é de autoridade. Esta é uma tensão vivenciada nas aulas de química, até mesmo por professores experientes. Por outro lado, os episódios analisados parecem indicar que os licenciandos participantes do PIBID fazem um movimento no sentido de valorizar a fala do estudante, mas ainda não têm completa segurança para manter uma abordagem dialógica por um longo período.

A utilização de perguntas durante as aulas é um fator que ajuda na introdução da abordagem interativa dialógica, porém acreditamos que é com a prática e a experiência que os futuros professores podem caminhar para manter essa abordagem por tempo suficiente para construir os conceitos junto com os estudantes e os mesmos alcançarem o discurso científico e dele se apropriarem.

Os episódios apresentados neste trabalho apontam para o esforço realizado pelos licenciandos no sentido de colocar em prática as discussões realizadas no PIBID sobre abordagem comunicativa e entender o seu papel nas aulas de química. É importante que os licenciandos tomem consciência da sua atuação, só assim poderão adquirir segurança na condução de aulas cada vez mais dialógicas, pois isso faz parte da valiosa formação que o licenciando adquire participando do PIBID. Acreditamos que os resultados desta pesquisa, que serão apresentados aos participantes do PIBID, poderão contribuir para as discussões sobre o tema. 


\title{
Discursive practices in teaching Chemistry: a study of the classes of future teachers of the Institutional Program of Initiation to Teaching
}

\begin{abstract}
This article presents the discursive practices identified in Chemistry classes of future teachers of the Institutional Program of Initiatives for Teaching - PIBID. These classes were observed during the development of the Water in Focus project: Quality of Life and Citizenship. The objective of the research was to understand how the communicative approach are produced in chemistry lessons of the future teachers participants of the PIBID. For data collection were filmed three lessons taught by three scholars each class in a class of second year high school students of a school in the city of Belo Horizonte-MG. In data analysis, we use the analytical tool proposed by Mortimer and Scott (2003 and 2002) to identify the classes of Communicative Approach and the types of questions present in class. From the footage, we elaborate episodes maps in which we selected an episode of each lesson. In these episodes, we observed at the questions that the future teacher directed the class and from the questionings carried out seek to identify the types of Communicative Approach. The analysis of the data allowed us to identify the effort made by future teachers to promote an interaction with students emerging the different types of communicative approach. We also observe that questions of the process and metaprocess facilitate the emergence of the interactive dialogical approach.
\end{abstract}

KEYWORDS: PIBID. Communicative Approach. Training of Teachers. 
NOTA

1. Nesta pesquisa os licenciandos receberam nomes fictícios para preservar a identidade dos sujeitos.

\section{AGRADECIMENTOS}

CAPES pelo Programa Institucional de Bolsa de Iniciação à Docência (Pibid).

\section{REFERÊNCIAS}

ALMEIDA, S. A.; GIORDAN, M. Discursos que Circulam na Correção de um Questionário: Sentidos e Significados. Revista Ensaio, Belo Horizonte, MG, v.14, n.3, p. 239-259, 2012.

Candela, A. El discurso argumentativo de la ciencia en el aula. Encontro sobre teoria e pesquisa em ensino de ciências. Belo Horizonte, 1997.

DUARTE, F. C. T. Práticas discursivas: Como aparecem nas aulas de intervenção dos licenciandos do PIBID? Trabalho de Conclusão de Curso (TCC). Universidade Federal de Minas Gerais, Belo Horizonte, 2013.

DRIVER, R.; ASOKO, H.; LEACH, J.; MORTIMER, E. F.; SCOTT, P. Construindo o Conhecimento Científico na Sala de Aula. Química Nova na Escola, n. 9, 1999.

JIMÉNEZ-ALEIXANDRE, M. P. \& AGRASO, M. F. A argumentação sobre questões sóciocientíficas: processos de construção e justificação do conhecimento na sala de aula. Educação em Revista, n. 43, 2006.

LIMA, M. E. C. C. Formação Continuada de Professores. Química Nova na Escola, São Paulo, v.1, n.4, p.12-17, 1996.

MEHAN, H. Learning Lessons: social organization in the classroom. Cambridge, MA: Harvard Press, 1979

MONTEIRO, M. A. A.; TEIXEIRA, O. P. B. Uma Análise das Interações Dialógicas em Aulas de Ciências nas Séries Iniciais do Ensino Fundamental. Investigações em Ensino de Ciências, v.9, n.3, p. 243-263, 2004. 
MORTIMER, E. F.; SCOTT, P. H. Atividade Discursiva nas Salas de Aula de Ciências: Uma Ferramenta Sociocultural para Analisar e Planejar o Ensino. Investigações em Ensino de Ciências. Porto Alegre, RS, v.7, n.3, p.7, 2002.

MORTIMER, E. F.; SCOTT, P. H. Meaning Making in Secondary Science Classroom.1.ed. Maidenhead: Open University Press/McGraw Hill, 2003.

SILVA, P. S. O Projeto Temático na Sala de Aula: Mudanças nas Interações Discursivas. Universidade Federal de Minas Gerais, 2009.

SILVA, P. S.; MORTIMER, E. F. O Projeto Água em Foco como uma Proposta de Formação no PIBID. Química Nova na Escola, v.34, 2012, p.240-247.

SILVA, A. C. T. Estratégias Enunciativas em Salas de Aula de Química: Contrastando Professores de Estilos Diferentes. Universidade Federal de Minas Gerais, 2008.

SILVA, A. C. A. da. A Dialogia No Ensino De Ciências: Um Estudo Do Desenvolvimento Do Discurso Em Sala De Aula. Tese (Doutorado em Educação). Universidade Federal de Minas Gerais, Belo Horizonte, 2015.

\section{ANEXO I}

\section{PERGUNTAS BEATRIZ}

- O que nós fizemos na aula passada?

- Vocês lembram as cores da nossa escala?

- Onde vai ficar a substância ácida, a básica e a neutra, nessa nossa escala?

- Se eu não conheço a escala de pH, como eu vou saber se a substância é ácida ou básica, somente usando sua fórmula?

- Alguém sabe me dizer um exemplo de uma substância ácida? - E uma substância básica que a gente consome no dia a dia? - Qual foi o primeiro ácido que a gente analisou na prática? - O que essas substâncias têm em comum só de olhar para as fórmulas delas? - O que a substância neutra vai liberar num meio?

- Quem serão meus produtos da auto ionização da água?

- Alguém sabe o que significa $\mathrm{pH}$ ?

- Se eu estou medindo a quantidade de hidrogênio que eu tenho no meio, quando eu to analisando uma substancia ácida, ela vai ter o que lá no meio? Em grande ou em pouca quantidade? 
- Na nossa faixa de $\mathrm{pH}$, quem tem o maior $\mathrm{pH}$ ? - O que nós usamos para verificar o pH da substância (na aula prática)? - Quantas cores a gente tinha na escala de pH que construímos? - agora, por que vocês acham que a gente está analisando esse $\mathrm{pH}$ ? - Alguém sabe se é em alto ou em baixo $\mathrm{pH}$ que a vida aquática consegue sobreviver? - O que vocês acham que acontece com a reprodução dos peixes? - Eu coloquei esse ovo dentro do vinagre, o que é o vinagre?

- O que está acontecendo aqui dentro (do potinho de ovo com vinagre)? (formação de bolhas) Essa formação de bolhas significa o que? O que está acontecendo? (corroendo o ovo) é uma reação química?

- Alguém sabe do que é formada a casca do ovo? E o que eu tenho lá no meio? - se eu tenho esses íons, o que pode formar lá dentro? - se eu tiver um pH muito ácido o peixe vai conseguir reproduzir? Por quê?

\section{PERGUNTAS SARA}

- Qual foi nosso objetivo na aula prática? - Era ver o pH? Era medir o pH?

- Qual cor que ficou? - Do pH 1 a 6 , a substância é o que? E 7?E do 8 ao 14? O que é uma solução ácida? O que é uma solução básica? Conceito. - o ácido sulfúrico vai liberar o que em água?

- Quais as bases que nós usamos na prática? - o $\mathrm{NaOH}$ em água, o que vai liberar?

- E em caso da substância neutra? O que podemos dizer com relação a liberação de $\mathrm{H}+$ e $\mathrm{OH}$ - na substância neutra? Como sabemos que a substância é neutra?

- O que o pH mede? - Como que uma substância indicadora ácido-base vai funcionar?

- A substância estava de uma cor, pinguei outra substância e mudou de cor. Isso é evidência de que?

- O extrato de repolho mostrava quais cores?

- Eu consigo explicar o extrato de repolho roxo só com essa equação aqui? Como será que vai funcionar o extrato de repolho roxo?

Mistura das cores? Soma das cores? Vai mudando e mudando as cores (acontecendo outras reações)? (respostas dos alunos) ela mostra que uma resposta está errada, usando a tabela de cores que os alunos obtiveram, os alunos mesmo entendem que a reposta não era válida. E depois explica e confirma a outra resposta.

- Vinagre é ácido ou base? E hidróxido de sódio? - Eu tenho um ácido e uma base aqui, só olhando dá para identificar?

- Qual o objetivo do projeto água em foco? O que o $\mathrm{pH}$ tem a ver com a qualidade da água? (alunos: vida aquática) o pH vai influenciar na vida aquática? 
- Quando corrói os tubos da COPASA, quais metais serão liberados na água? (ovo no vinagre) $O$ que vocês estão vendo aqui? - formação de gás é evidência de quê? - o vinagre é ácido ou base? E todo ácido tem o quê?

- Do que é formada a casca do ovo?

- Nesta reação, alguém arrisca o que será formado aqui? Sabemos que vai formar um gás, qual gás? O que mais está faltando?

- O que isso vai influenciar na reprodução dos peixes?

\section{PERGUNTAS DANIEL}

- Quem lembra o que aconteceu no experimento de pH que fizemos? - Como essa mudança de cor ocorreu?

- Nós adicionamos coisas e a cor do extrato de repolho roxo mudou. O que essas coisas eram? - quando vocês adicionaram ácido, vinagre, qual cor ficou? - e quando vocês adicionaram soda cáustica, que cor ficou? - entre esses ácidos, qual vocês acham que é o mais ácido?

- Alguém aqui misturou os conteúdos dos tubos depois do experimento? 0 que aconteceu? - o que tem no vinagre que faz ele ser ácido? - Descrevam como que está a superfície do ovo. - A presença de bolhas indica alguma coisa para vocês?

- Quais evidências que vocês conhecem que indicam uma reação química? (o ovo mudou, está diferente, está fedendo) - Será que bolhas é uma indicação de reação química? - Com é que vamos balancear essa equação? - mas o que isso tem a ver com a qualidade da água?

Recebido: 05 jan. 2018

Aprovado: 30 jul. 2018

DOI: $10.3895 /$ actio.v3n2.7594

Como citar:

SILVA, A. C. A. As práticas discursivas no ensino de química: um estudo das aulas dos licenciandos do programa institucional de bolsas de iniciação à docência. ACTIO, Curitiba, v. 3, n. 2, p. 195-213, mai./ago. 2018. Disponível em: <https://periodicos.utfpr.edu.br/actio>. Acesso em: XXX

Correspondência:

Ana Carolina Araújo da Silva

Rua Elói Américo Mendes, n. 75, Bairro Aeroporto, Juiz de Fora, Minas Gerais, Brasil.

Direito autoral: Este artigo está licenciado sob os termos da Licença Creative Commons-Atribuição 4.0 Internacional. 